\title{
Avaliação de falhas via teste de movimentação em juntas de expansão usadas
}

\author{
Failure evaluation on used expansion joints \\ using a movement test
}

Veiga, J.L.B.C.; Medeiros, J.

PETROBRAS, Petróleo Brasileiro S.A., CENPES - Centro de Pesquisa da Petrobras.

Av. República do Chile, $n^{\circ}$ 65, Centro, cep 20031-912, Rio de Janeiro, RJ.

e-mail:jordana@petrobras.com.br ; jorivaldo@petrobras.com.br

\begin{abstract}
RESUMO
É apresentada uma breve descrição do teste de movimentação aplicado às juntas de expansão de grande porte, bem como a aplicação desse teste em sistemas em operação para avaliar danos oriundos de eventuais ocorrências. Após ocorrência em um sistema de turbo expansor foram realizadas inspeções visuais nas juntas de expansão dos dutos de gases de combustão e apesar da inspeção não mostrar danos nesses componentes, os testes de movimentação no campo, realizados com o sistema pressurizado e não pressurizado, indicaram severa restrição na movimentação das juntas de expansão. Em função dos resultados dos testes de campo, decidiu-se pela remoção das juntas de expansão para reparo em fábrica, onde novas inspeções e testes foram realizados na oficina de um fabricante confirmando os resultados de campo. A inspeção mais detalhada em fábrica confirmou a presença de interferências nos componentes das juntas, provocadas por deformação excessiva dos mesmos, o que corroborou a decisão da retirada das juntas para manutenção em fábrica. O teste de movimentação se confirmou como método prático fundamental para avaliação de desempenho mecânico de linhas críticas, não só para sistemas novos como para sistemas que já estiveram em operação, e que pode ser aplicado em outros sistemas de tubulação, não sendo restrito a dutos de gás de combustão.
\end{abstract}

Palavras-chave: Junta de expansão, tubulações, avaliação de falha; FCC; teste de movimentação a frio.

\begin{abstract}
A brief description of a test executed in large expansion joints, and the application of this test systems in operation to assess damage from emergencies. After an event in a turboexpander system, visual inspections were carried out in the expansion joints of the flue gas ducts and despite the fact that the inspection did not show damage to these components, a motion field test were conducted with the system pressurized and unpressurised, and indicated severe restriction in the movement of the expansion joints. With the field tests results, it was decided to remove the expansion joints for in shop repair where new inspections and tests were performed in the factory of a manufacturer confirming the results of field. A more detailed inspection at the factory confirmed the presence of interference in the components of joints caused by excessive deformation, which confirmed the decision of removal the joint for maintenance. The movement test was confirmed as essential practical method for assessing mechanical performance of critical lines not only for new systems but also for systems that have already been in operation, which can be used in other pipeline systems and is not restricted to ducts flue gas.
\end{abstract}

Keywords: Expansion joints, pipes, evaluation of failure, FCC, cold movement test. 


\section{INTRODUÇÃO}

Unidades de Craqueamento Catalítico Fluido de Resíduo (RFCC, do inglês "Resid Fluid Catalitic Cracking”), possuem grande potencial de geração de energia elétrica aproveitando a energia dos gases quentes de combustão resultantes da queima do coque que impregna o catalisador responsável pelas reações do processo de craqueamento. Os gases podem ser $\mathrm{CO}_{2}$ (queima completa) ou $\mathrm{CO}$ (queima incompleta). A energia elétrica é gerada a partir em um gerador que é acionado por um turbo expansor que utiliza a energia térmica presente nos gases de combustão para movimentar a máquina.

Para que o processo de geração de energia seja máximo é importante que a perda de carga na tubulação que conduzirá os gases de combustão do vaso de pressão de $3^{\circ}$ estágio até o turbo expansor seja mínima e para tanto é necessário que seu traçado seja o mais curto possível.

O turbo expansor é uma máquina rotativa de grande porte que opera em condições severas de temperaturas de até $760^{\circ} \mathrm{C}$ em condições normais de operação e baixas pressões, comumente não superiores a $3,5 \mathrm{kgf} / \mathrm{cm}^{2}$. Esta máquina possui a particularidade de sua carcaça ser pouco resistente a esforços externos oriundos principalmente da movimentação da tubulação por dilatação térmica.

Devido a necessidade de traçado enxuto, aliado a baixa resistência da carcaça da máquina a esforços externos [1] faz-se necessário o uso de juntas de expansão no sistema [2], para que mesmo com um traçado curto não sejam transmitidos à máquina esforços superiores à sua capacidade.

Sistemas de turbo expansor possuem dutos, tanto de admissão como exausto, de grandes diâmetros, acima de 40 polegadas. Estes dutos podem apresentar diferentes soluções para sustentação: suportes de mola de carga constante, suporte tipo tirante, guias, anti-rotacionais, suportes de contra-peso, suportes fixos com came, entre outros. A seleção do tipo de suporte adequado ao sistema depende diretamente da análise de flexibilidade realizada nos dutos e do arranjo de estruturas, equipamentos e linhas existentes no entorno dos dutos e do turbo expansor.

O sistema de duto de entrada da máquina (admissão) possui duas válvulas borboletas. A primeira válvula tem por objetivo o bloqueio rápido. Seu fechamento deve ocorrer em menos de 0,6 segundos com o intuito de proteger a máquina caso ocorra alteração brusca no fluxo e para evitar também flutuações no processo da RFCC. A segunda válvula tem por objetivo o controle do fluxo de gases. Estas válvulas não garantem estanqueidade e para que seja permitida manutenção ou qualquer tipo de intervenção na máquina ou no duto é necessário que haja estanqueidade total. Para que isto seja possível, em algumas unidades, é necessária a utilização de "figura 8", raquetes, ou remoção de carretéis para instalação de flanges cegos, que também necessitam da exposição humana para seu acionamento. Sendo então necessária a parada da unidade para sua colocação. Algumas unidades possuem válvula isoladora, que pode ser fechada e aberta sem que ocorra vazamento do fluxo para o meio externo. Qualquer um dos tipos de dispositivo escolhido deve ser colocado nos dutos de admissão e exausto da máquina,

Com objetivo de avaliar sistemas de tubulações de grande porte ligados a máquinas que resistem somente a pequenos esforços [1], foi desenvolvido um teste de movimentação a frio dos dutos ligados a este tipo de máquina. Este teste de movimentação é utilizado para avaliação de sistemas de tubulação ligados a turboexpansor desde o início de sua implantação na PETROBRAS. São utilizados pós-montagem para certificação do correto funcionamento de juntas de expansão presentes no sistema e para a detecção de interferências oriundas da construção e montagem. Mais recentemente, o teste também passou a ser aplicado diretamente nas juntas de expansão para atestar seu bom funcionamento, após a conclusão da fabricação, ainda na fábrica. Com isto, entre outras coisas, é possível conhecer a rigidez real da junta de expansão (JE) e, eventualmente, ajustar o modelo numérico de análise de flexibilidade.

\section{DESENVOLVIMENTO}

No sistema de turboexpansor da URFCC em estudo o duto de admissão possui diâmetro superior a 60", 4 juntas de expansão [2], 2 tipo cardânicas e 2 tipo dobradiça, 2 válvulas borboletas, 7 pares de suporte de mola de carga constante e 2 pares de tirantes rígidos. No trecho vertical estão as 2 juntas de expansão cardânicas e 4 pares de suporte de mola (Figura 1), no trecho horizontal de entrada no turboexpansor estão as 2 juntas de expansão dobradiça e 3 pares de suporte de mola e 2 pares de tirantes rígidos. 


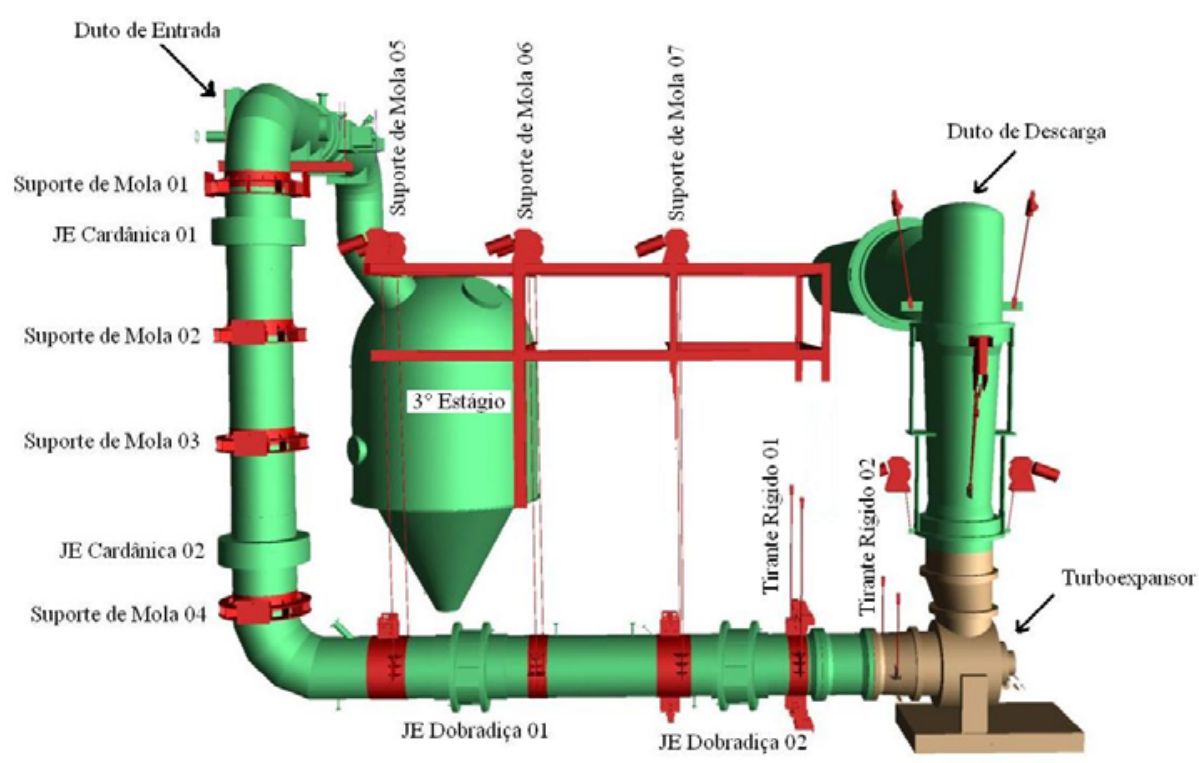

Figura 1: Visão geral do sistema de turboexpansor.

Esta unidade de RFCC operando com turboexpansor acoplado para geração de energia elétrica apresentou problemas operacionais de disparo de temperatura. Havendo suspeita de temperaturas acima da de projeto. A máquina foi parada em função do nível de vibrações detectado estar acima do limite de operação da máquina, indicando possível roçamento do rotor com a carcaça.

Após a parada da máquina foi realizada inspeção visual do sistema e neste momento foi constatada falha na suportação dos dutos (Figura 2), assentamento do duto de admissão em vigas de estruturas adjacentes (Figura 3), confirmando o adernamento da linha, e trincamento em rolamentos de suportes.

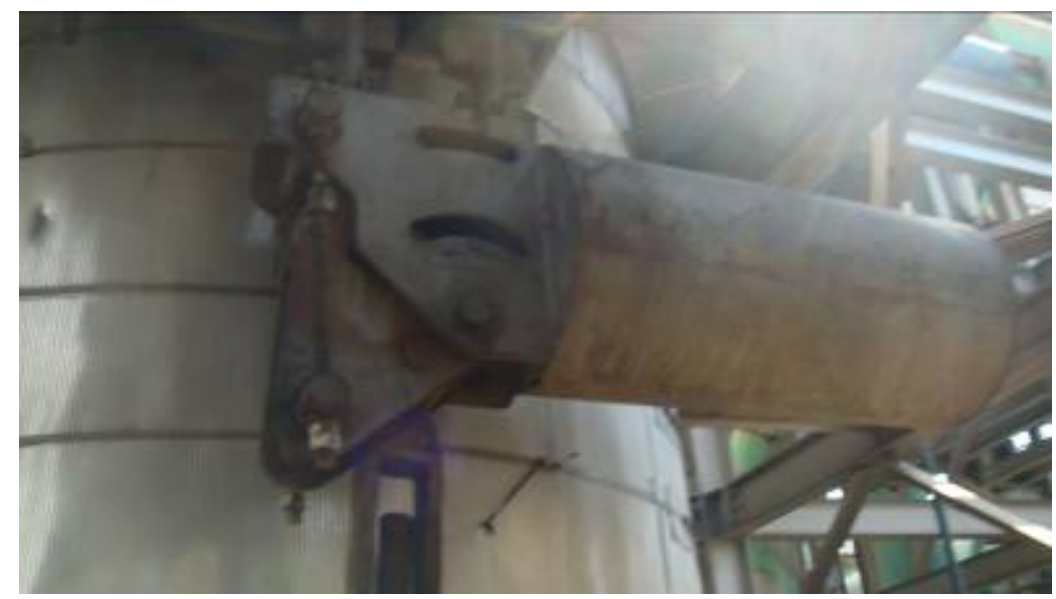

Figura 2: Suporte Mola.

As avaliações e testes se concentraram no duto de admissão onde foram observados danos mais severos. Além disso, as temperaturas registradas a partir do bocal de admissão do turbo expansor ficaram abaixo das de projeto, provavelmente pela contínua injeção de vapor no sistema próximo ao bocal de entrada da máquina, com o propósito de redução de temperatura. Assim, o duto de exausto não sofreu danos pela ocorrência. 


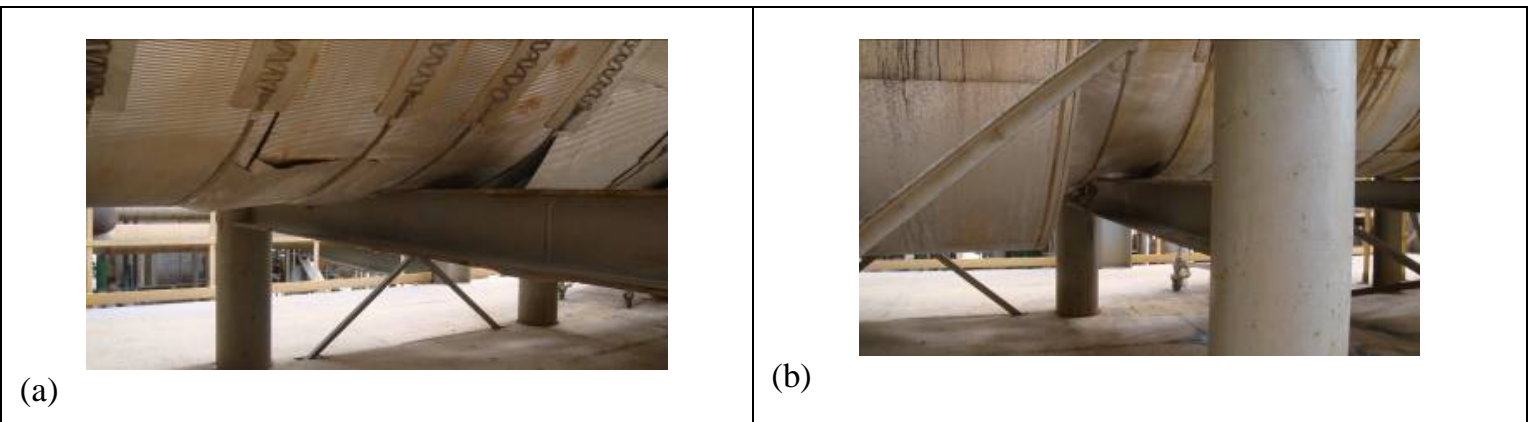

Figura 3: Adernamento do Duto de Admissão (a) e (b).

Após a inspeção visual e suas constatações, foi necessário isolar o sistema, para melhor avaliação dos danos ocorridos e avaliação do turboexpansor. Com o duto isolado da máquina, mas ainda conectado ao vaso de $3^{\circ}$ estágio foram realizados os primeiros testes de movimentação para avaliação da flexibilidade do duto de admissão.

Antes da execução de qualquer item do teste de movimentação de dutos sempre é feita varredura no sistema, observando estado e posição de guias, suportes fixos e de mola. Todas as juntas de expansão são observadas quanto a sua posição inicial e possíveis interferências que já existam, e é dada atenção especial aquelas juntas que irão trabalhar durante o teste. O duto de entrada do turbo expansor também é inspecionado, de forma a encontrar interferências ou pontos que com a sua movimentação possam interferir de alguma forma. Como referência para a posição a frio (de montagem) e a quente (com o turbo em operação) dos suportes de mola e das juntas de expansão, foi utilizado o relatório de acompanhamento de partida e operação da planta.

Durante a inspeção visual foi constatada a necessidade de manutenção nos quatro pares de suporte de molas do trecho vertical, e também que os foles das juntas da horizontal estavam furados e necessitavam intervenção, troca ou colocação de fole externo. As guias do sistema também necessitavam de manutenção e ajuste (Figura 4).

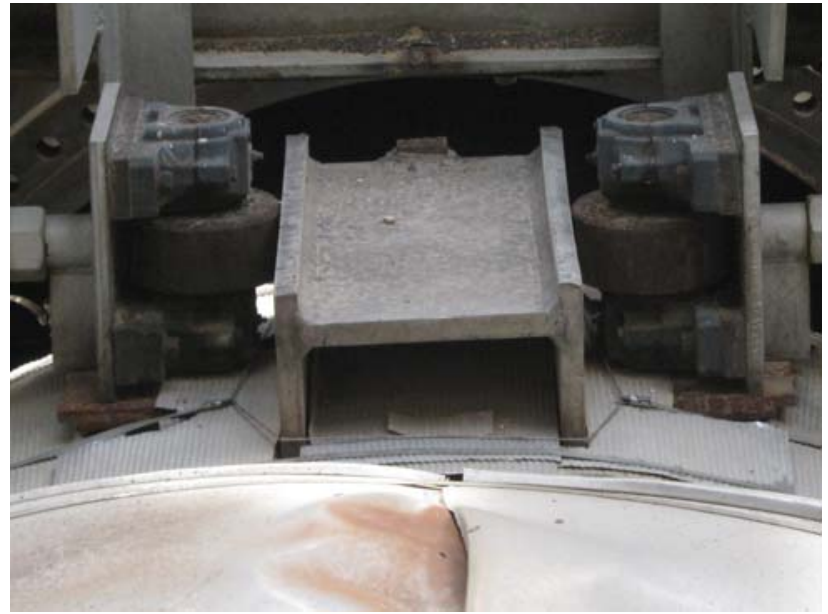

Figura 4: Detalhe da guía instalada.

Os resultados de testes de movimentação evidenciaram dificuldades de deslocamento da linha do turbo, em magnitudes significativamente maiores que as do histórico dessa linha (na última alteração de projeto do sistema foram realizados e registrados os resultados do teste de movimentação a frio). O valor do carregamento necessário para imprimir mesmo deslocamento que no teste anterior foi bem maior neste teste, inclusive com comportamento compatível com o travamento do sistema sem que tenham sido detectadas quaisquer interferências externas no duto ou nas JE.

Com os resultados do teste de movimentação avaliaram-se as possíveis causas da carga excessiva para movimentação da linha. Entre as causas foram listados: pino da JE engripado devido ao excesso de temperatura; garfos do hardware da JE danificados devido ao disparo de temperatura; danos na camisa interna da JE. Não foi incluído como uma das possíveis causas do aumento na carga devido ao fato das JE 
estarem pressurizadas na condição de teste, quando comparadas com os resultados do teste histórico de referência, realizado sem pressão no sistema, pois esta diferença já foi estudada e não é superior a 40\% [3], e nos resultados encontrados o valor é superior em mais de $300 \%$.

Dentre as possíveis causas, optou-se por investigar inicialmente a que não necessitaria da parada da unidade para isolar o duto de entrada em relação ao $3^{\circ}$ estágio. Foi feita então, intervenção para retirada dos pinos das JE (Figura 5) e realizada manutenção nas superfícies de contato para diminuir possíveis travamentos.

Os testes de movimentação foram repetidos e os resultados não sofreram alterações significativas. Para prosseguir no tratamento do problema foi isolado o sistema do duto de admissão viabilizando o acesso para inspeção interna das JE, principalmente as do trecho vertical.

Com o sistema aberto foi possível realizar inspeção interna com a JE instalada no duto e não foi constatado danos nas camisas internas que pudessem comprometer a movimentação do sistema, mas sua interferência neste momento ainda não foi descartada pela pequena folga existente entre a camisa e a JE. O teste de movimentação foi então repetido, com o sistema despressurizado, mas não houve alteração além da já esperada pela redução da pressão [4]. Foi constatado o enrijecimento do sistema, com provável interferência do "hardware” e camisa das juntas de expansão. Desta forma foi recomendada a remoção das JE para recondicionamento e troca dos foles, e avaliação da rigidez das JE em separado através de teste em fábrica, similar aos testes de fabricação feito para JE novas.

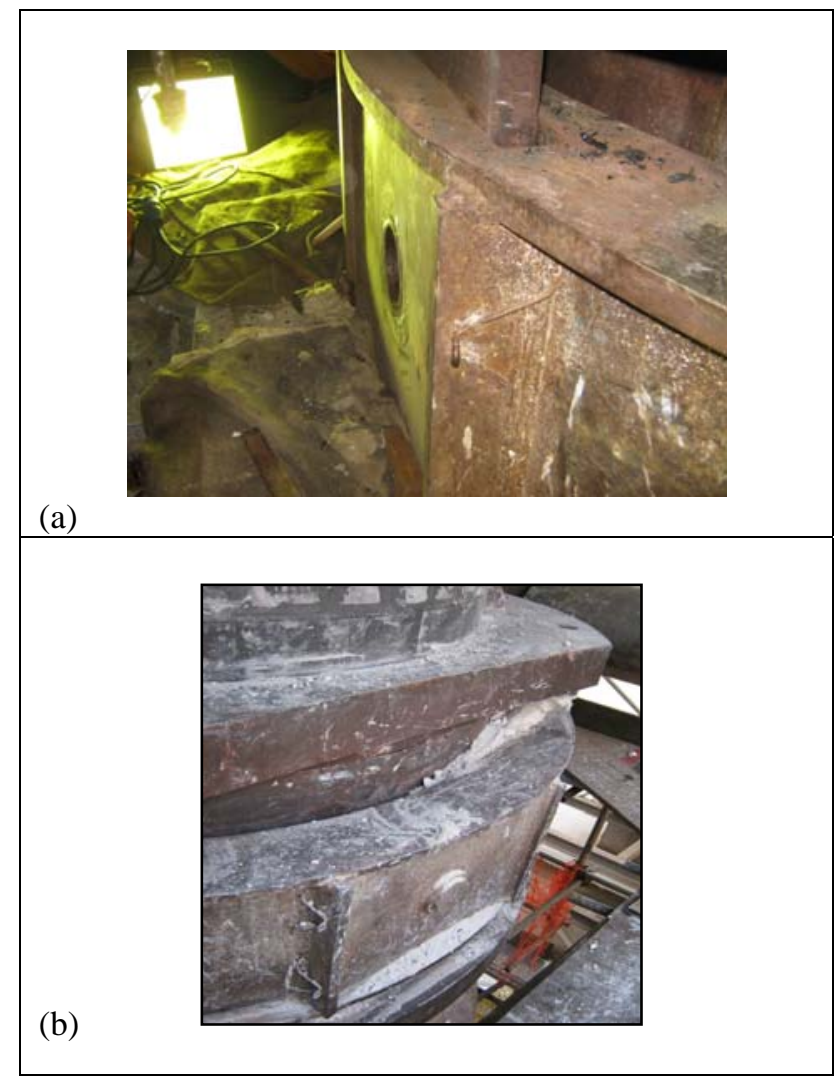

Figura 5: Detalhe dos Pinos de Rótula da JE.

Antes da retirada das JE o sistema foi simulado em um programa de análise de flexibilidade de forma a confirmar o comportamento de travamento das JE. O resultado da análise realizada está apresentado na Figura 6. Nele é possível observar que a inclinação das curvas, que representa a rigidez do sistema, se assemelha entre os resultados dos testes 01 e 02 e da simulação com o travamento das JE 1 e 2. De posse dos resultados do teste de campo e da simulação foi confirmada a necessidade de abertura do sistema e verificação individual das JE. 


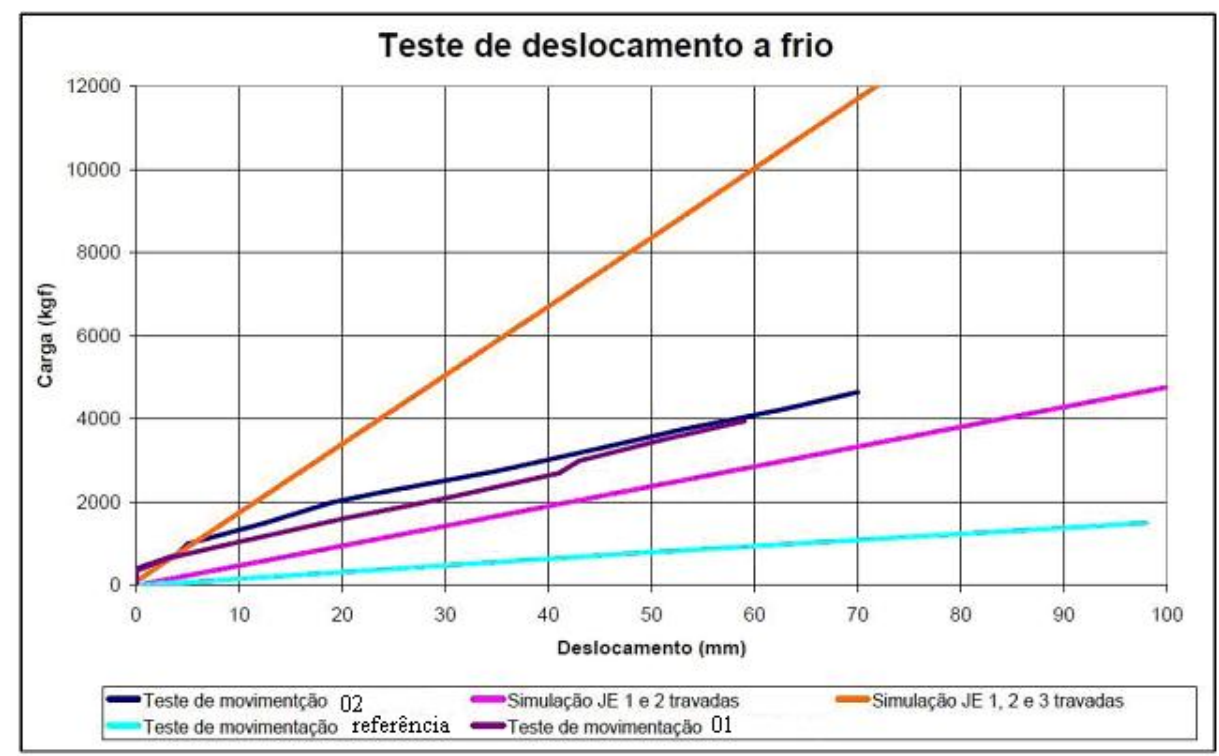

Figura 6: Simulação do Teste de Movimentação a Frio.

Além do recondicionamento do sistema (JE, suportes de mola e guias) optou-se por simplificá-lo, reduzindo o número de JE que poderia deixar o sistema instável. Assim uma das JE do trecho horizontal (Figura 7) foi removida e substituída por um carretel.

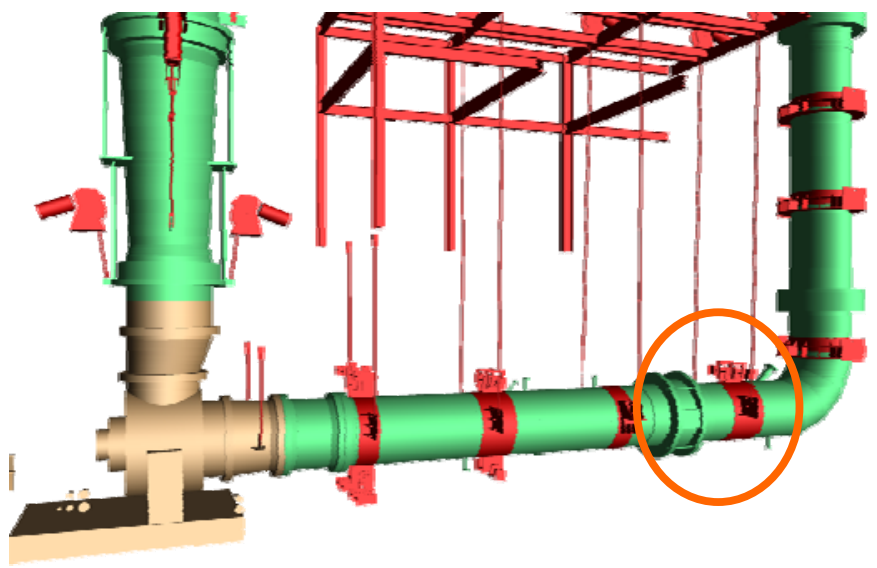

Figura 7: Posição da JE Removida.

\section{METODOLOGIA}

O teste de movimentação a frio possui metodologia de fácil execução e amplamente explicada $[3,4,5]$. Ele consiste em se desconectar o duto, de admissão e/ou exausto, do turboexpansor e movimentar a linha mecanicamente do valor esperado em operação oriundo da dilatação térmica, os possíveis pontos para desconexão podem ser observados na Figura 8, assim como o ponto sugerido de conexão para o teste e as direções do movimento. Desta forma, o sistema é observado e percorrido fisicamente para que sejam encontradas interferências externas ocorridas com a movimentação do duto, tais como contato com plataforma, estrutura, linhas, roçamento do isolamento com os suportes, contato dos tirantes de suporte com estrutura e/ou plataforma, entre outros. Observa-se também, as juntas de expansão quanto ao ângulo de movimentação e direção, e é analisada a carga necessária para movimentar a linha do deslocamento esperado. Este valor deverá ser compatível com os valores de rigidez combinados oriundos dos cálculos teóricos pelo EJMA, “Expansion Joint Manufacturer Association” [6], e da análise de flexibilidade do sistema e, caso tenha sido realizado, dos testes de movimentação a frio em fábrica. 


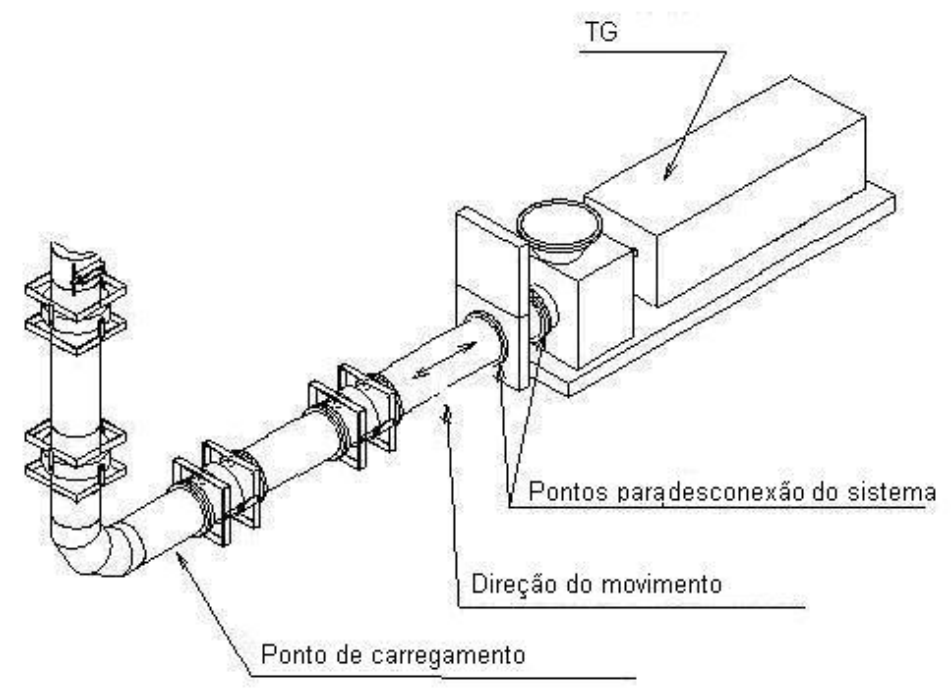

Figura 8: Esquema do Teste de Movimentação a Frio de Dutos com JE.

O passo seguinte foi realizar o teste de movimentação a frio de cada uma das JE do sistema na fábrica, em separado $[3,4,5]$. Cada JE teve soldado a ela dispositivo que permite realizar movimentação com a JE de forma controlada e sendo possível registrar o movimento e a carga necessária para aquele movimento dado.

O teste consiste na colocação da JE sobre um sistema de sustentação e posicionamento na vertical. As extremidades da JE são fechadas com um tampo soldado, quando há a necessidade de se realizar o teste com pressão. Neste estudo os testes foram realizados sem pressão na JE. O dispositivo possui uma viga I soldada no tampo superior com um braço de alavanca de 2 m (Figura 9), correntes, talha e dinamômetro digital para aquisição da carga [5].

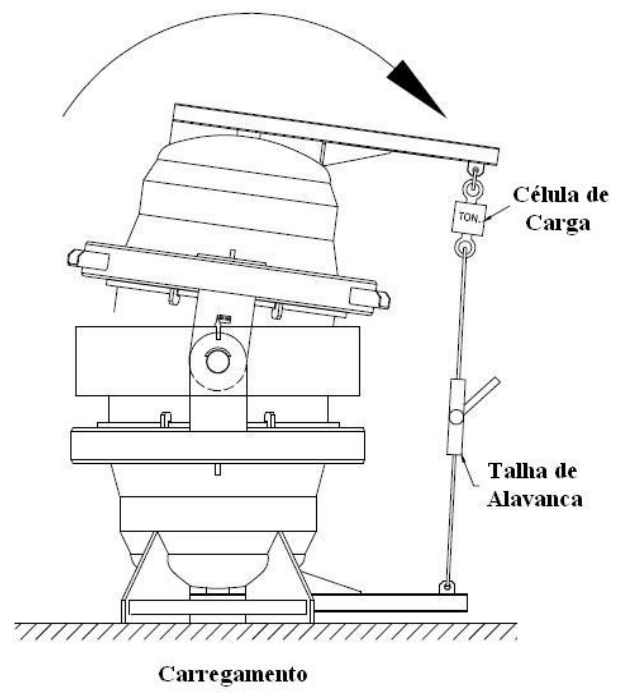

(a)

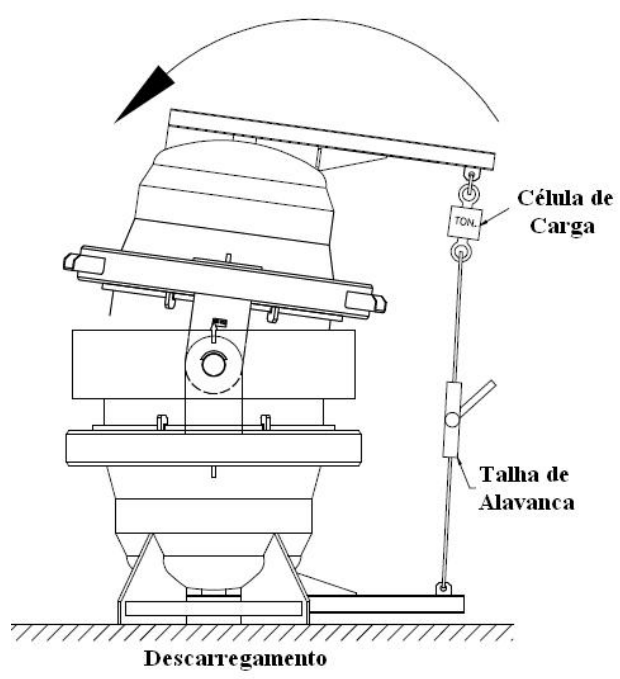

(b)

Figura 9: Esquema de Carregamento e Descarregamento do Ensaio [5]

\section{ANÁLISE E DISCUSSÃO DE RESULTADOS}

Após remoção das JE do duto onde estavam instaladas elas foram levadas até “pipeshop” de um fabricante para inspeção visual, testes de recebimento, recondicionamento e testes de finalização do recondicionamento. 
Foram observadas alterações dimensionais no "hardware" das JE, tais como empenamento (Figura 10). Que confirmaram a necessidade de recondicionamento. A troca dos foles foi necessária pela presença de furos.

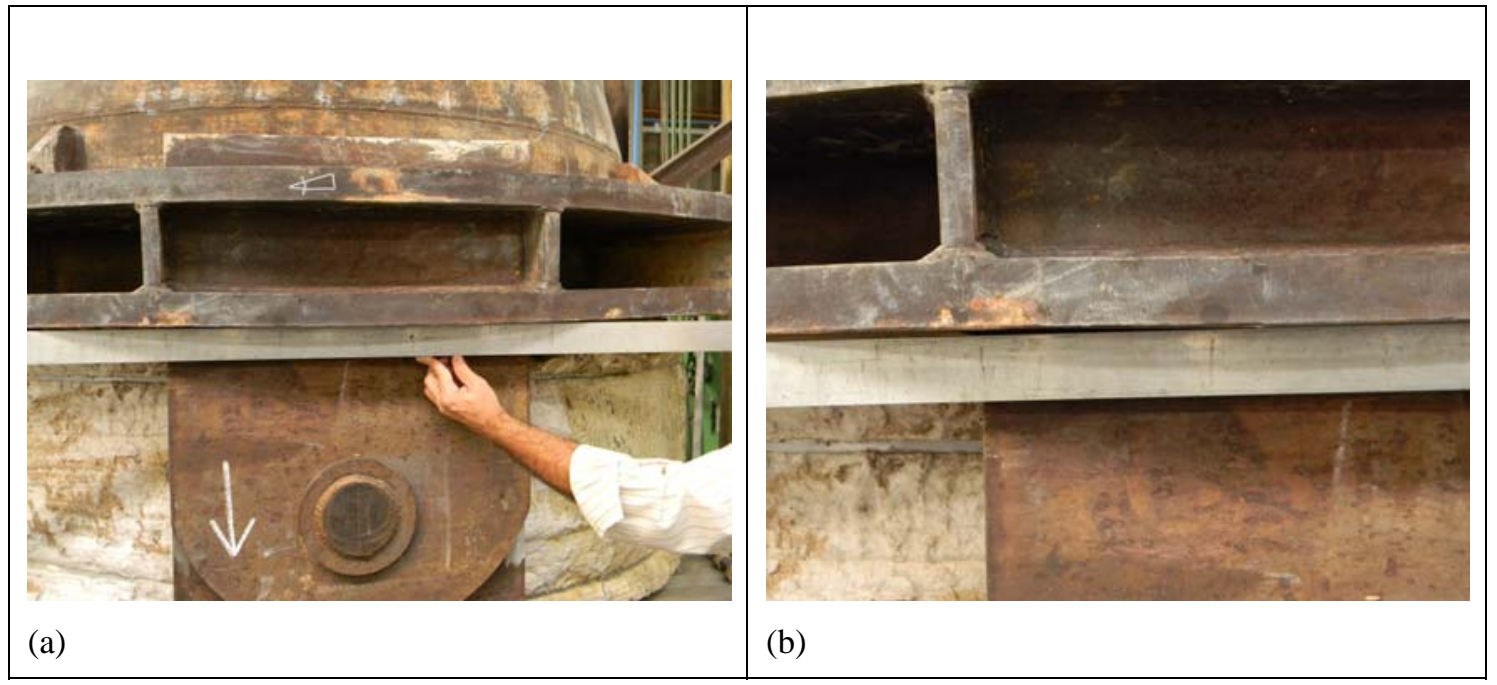

Figura 10: (a) Empenamento da JE, (b) detalhe.

Conforme já explicado as JE foram testadas em fábrica assim que recebidas e testadas após recondicionamento e troca de fole.

As Figuras 11 a 13 apresentam os valores encontrados nos testes de movimentação a frio e sem pressão das JE em fábrica, antes e após recondicionamento. A Figura 11 mostra os resultados de uma junta do tipo dobradiça, instalada no trecho horizontal do sistema. A Figura 12 mostra os resultados da JE tipo cardânica 01 instalada no trecho vertical do sistema e a Figura 13 da JE tipo cardânica 02 também instalada na vertical. Nas três figuras são apresentadas três curvas, o teórico pelo padrão de fabricantes, que é o EJMA [6], a curva antes do recondicionamento e após o recondicionamento.

Pela Figura 11 podemos observar a diferença de rigidez entre a JE antes do recondicionamento e o teórico proposto. Após o recondicionamento observa-se que houve grande diferença na rigidez comparada com antes do recondicionamento, tendo inclusive ficado abaixo do teórico proposto pelo EJMA [6].

\section{Teste de deslocamento a frio - JE da Horizontal}

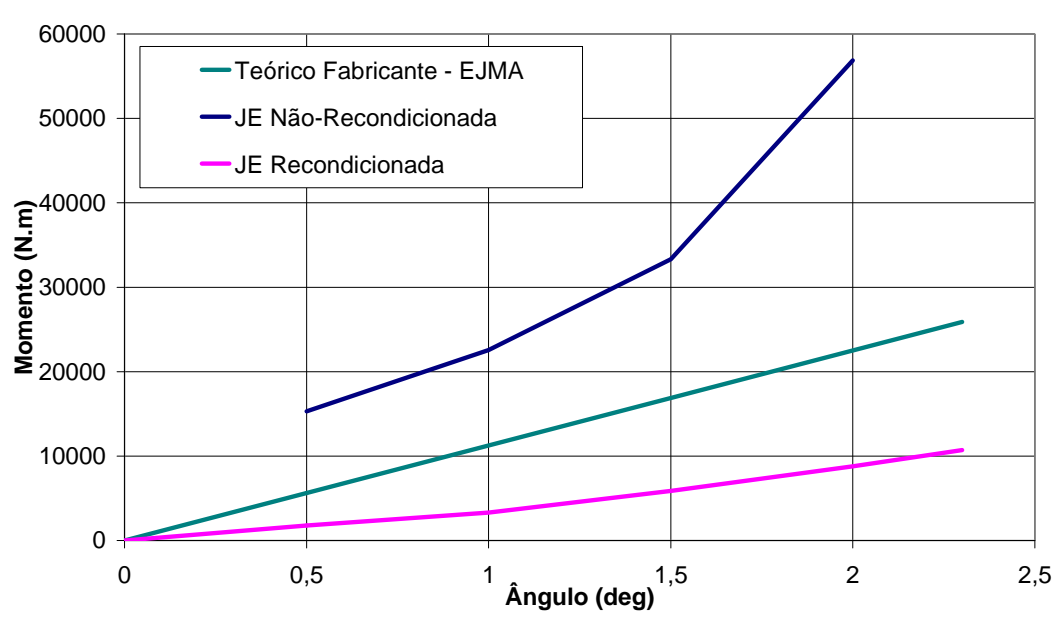

Figura 11: Teste de deslocamento a frio - JE da Horizontal.

Observando a Figura 12 nota-se que a JE não-recondicionada possui comportamento bi-linear, como se dois diferentes agentes governassem, em momentos diferentes, o comportamento da rigidez da JE. Após o recondicionamento a JE volta a ter comportamento linear simples e também obteve resultado de rigidez menor que antes do recondicionamento e inclusive abaixo do teórico 


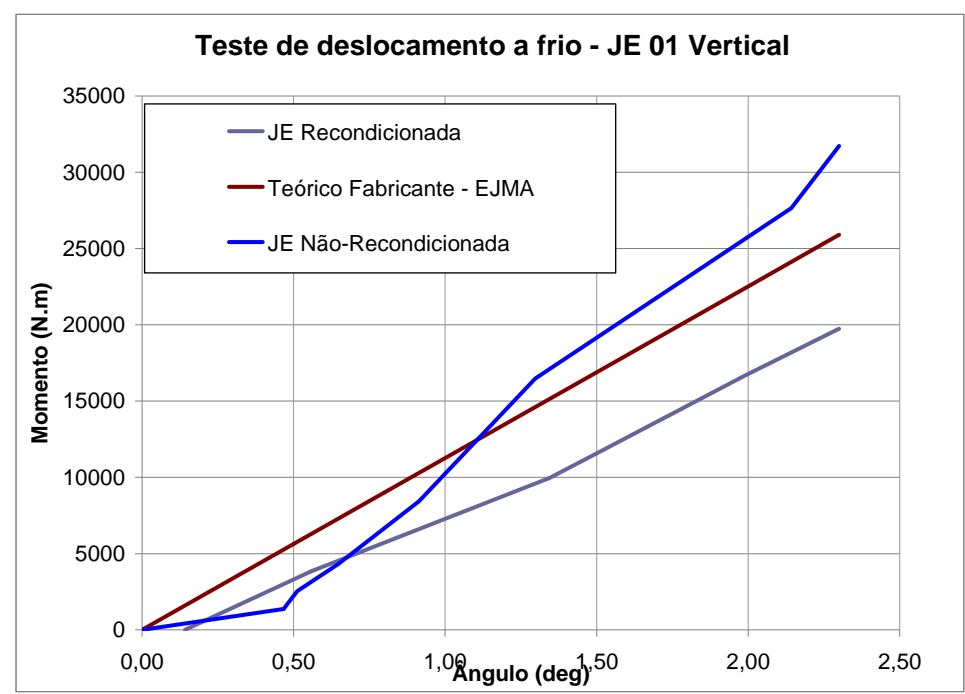

Figura 12: Teste de deslocamento a frio - JE 01 Vertical.

A Figura 13 mostra comportamento governado de forma diferente a cada angulação experimentada pela JE antes do recondicionamento e comportamento linear e abaixo do teórico após o recondicionamento.

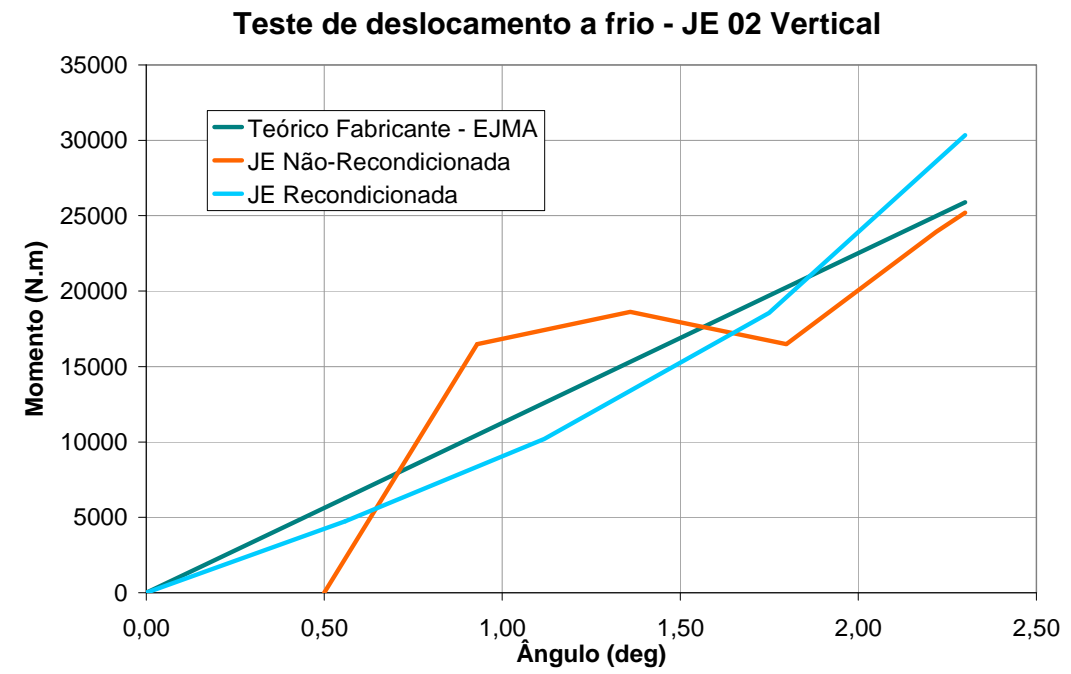

Figura 13: Teste de deslocamento a frio - JE 02 Vertical.

Com estes resultados todas as três JE foram reinstaladas no duto de entrada do sistema do turbo expansor e não apresentaram problemas no retorno à operação. Os suportes de mola também foram recondicionados e reinstalados, assim como as guias que utilizam rolamentos para redução do atrito durante movimento.

\section{CONCLUSÃO}

Após ocorrência, em turbo expansor em unidade de RFCC parou por excesso de vibração. Foi constatado que o sistema do duto de admissão estava com danos na sua suportação e apresentava adernamento acentuado.

Foram realizados testes de movimentação do duto para avaliar a rigidez do sistema que apresenta limite de esforços transmitidos pequenos devido ao turbo expansor. Os testes foram realizados em duas condições: linha pressurizada e sem pressão. Os resultados foram similares e indicam cargas superiores às admissíveis.

Foi constatado durante as avaliações que três das quatro JE apresentavam vazamento pelo fole. E com o enrijecimento do sistema, optou-se pelo recondicionamento das JE em fábrica. 
Antes do recondicionamento em fábrica foram feitos testes de movimentação investigativos de forma a obter o comportamento rígido antes do recondicionamento e troca de foles. Após a troca e o recondicionamento os testes foram repetidos como procedimento de aceitação e como forma de verificar as mudanças e registro das novas condições, para que com a realização do teste de movimentação a frio com as JE instaladas houvesse previamente o comportamento de cada JE individualmente conhecido.

O teste de movimentação da JE confirma-se como importante teste de recebimento e de descrição do comportamento individual de JE tanto para JE novas, já utilizado anteriormente, como para JE recondicionadas. O teste em fábrica também teve papel importante para confirmar a restrição de movimento, identificar pontos a serem melhorados e confirmar melhorias após o recondicionamento.

\section{BIBLIOGRAFIA}

[01] NEMA SM 23, Steam turbines for mechanical drive device, 1991.

[02] EJMA, A practical guide to expansion joints, New York, Tarrytown, 1985.

[03] VEIGA, J.L.B.C., MEDEIROS, J., VEIGA, J.C.C, “Juntas de expansão de grande porte: avaliação de teste de movimentação”. In: 10 Coteq, Bahia, 2009.

[04] MEDEIROS, J., VEIGA, J.L.B.C., VEIGA, J.C.C., “Analysis of FCC expansion joints movement test”. In: ASME Pressure Vessels and Piping Division Conference, PVP 2009-77828, pp. 153-161, Praga, República Checa, 26-30 de julho 2009.

[05] MEDEIROS, J., VEIGA, J.L.B.C., VEIGA, J.C.C., “Teste de movimentação de juntas de expansão de grande porte”. In: Rio oil\&gás expo and conference, setembro 2008.

[06] EJMA, Standard of the expansion joint manufacturers association, $8^{\text {th }}$ edition, 2003. 